\title{
CHIA
}

Chronicles of Health

Impact Assessment

Improving community health through health impact assessments

October 2020

VOLUME 5 IsSue 1

\section{METHODS TO CONDUCT A HEALTH IMPACT ASSESSMENT LEARNING COLLABORATIVE}

Cynthia Stone, DrPH, RN; Alison Redenz, MURP, AICP; Andrea Bochenek, MPH; Ellie Hansotte, MPH

\section{Abstract}

Background: Indiana University Richard M. Fairbanks School of Public Health (IU FSPH) and the Health and Hospital Corporation of Marion County, through the Marion County Public Health Department (MCPHD), created a Health Impact Assessment (HIA) Learning Collaborative. The purpose of the HIA Learning Collaborative was to strengthen the capacity of both the academic and community partners to carry out HIAs. Entities recognize the value of creating a collaborative team to assure personnel are trained and available to provide time and expertise for plan reviews, formal feedback, data reports, literature summaries, and input in potential health/social impacts related to projects, which can ensure these impacts are considered in development work. In addition, the MCPHD and IU FSHP intend to increase HIA capacity in Indiana and remain committed to including health impact data into non-health sector decision making.

Methods: The group planned to meet monthly over the year with the following learning objectives. A survey was created in Survey Monkey in order to evaluate the overall HIA Learning Collaborative experience and to assess whether or not the learning objectives were met. The survey consisted of 11 questions: nine were multiple choice and two were open-ended.

Results: The majority of the objectives were met.

Conclusion: There is interest in conducting HIAs in the future and several ideas were generated.

$\begin{array}{cl}\prod_{\text {IUPUI }} & \text { THE SOCIETY OF } \\ \text { PRACTITIONERS OF } \\ \text { REALTH IMPACT ASSESSMENT } \\ \text { RCHCHARD M. FAIRBANKS }\end{array}$




\section{Introduction/Background}

Indiana University Richard M. Fairbanks School of Public Health (IU FSPH) and the Health and Hospital Corporation of Marion County, through the Marion County Public Health Department (MCPHD), created a Health Impact Assessment (HIA) Learning Collaborative to be conducted over one year. The collaborative was formed with a small funding opportunity from the Indiana University Center for Translational Science, Community Health Engagement Program. MCPHD wanted to increase staff that were familiar with the steps of a HIA and were able to apply the HIA process with communitybased projects. The U.S. Department of Health and Human Services recommends HIA as one important resource for implementing many of the Healthy People 2020 Objectives, particularly those that focus on the social determinants of health (Healthy People 2020 Advisor Committee, 2010). The purpose of the HIA Learning Collaborative was to strengthen the capacity of both the academic and community partners to carry out HIAs. Entities recognize the value of creating a collaborative team to assure personnel are trained and available to provide time and expertise for plan reviews, formal feedback, data reports, literature summaries, and input in potential health/social impacts related to projects, which can ensure these impacts are considered in development work. In addition, the MCPHD and IU FSPH intend to increase HIA capacity in Indiana and remain committed to including health impact data into non-health sector decision making.

Additional partner organizations were invited to participate in the HIA Learning Collaborative, including the Top 10 Coalition, the YMCA of Greater Indianapolis, and the Indiana State Department of Health. A total of eight individuals from the various organizations routinely participated during the year- long collaborative sessions.
The learning collaborative members wanted to discuss the concept of Health in All Policies. This led to a video conference with a staff person at the National Association of City and County Health Organizations (NACCHO). NACCHO has been providing technical assistance to several local health departments about putting health into all policy discussions and evaluating the impact of this change. HIAs are one tool that can be employed to put health into the policies and programs of non-health sectors, which is the intent of Health in All Policies (American Public Health Association (APHA), 2012).

\section{Method for conducting HIA Learning Col- laborative}

The group planned to meet monthly over the year with the following learning objectives:

1. Describe the purpose, benefits, and challenges of a Health Impact Assessment.

2. Develop an in-depth knowledge of the process and analytic methods used in the assessment step.

3. Demonstrate the ability to think critically and analyze how the findings related to policy decisions.

4. Conduct an HIA on a local project/ process/ or policy.

A Canvas web-based course site was created from the learning management system at Indiana University to store materials and allow for sharing of information. Access to the course was generated by completing a guest account request. Several of the participants had previously used Canvas.

The textbook Health Impact Assessment in the United States by Ross, et al. (2014) was used for the background sessions of the HIA process. During the first five months, different steps of the HIA process were studied. Each session 
lasted for 90 minutes and covered the readings and discussion of application using the cases in the book (Ross et al. ,2014). The session following the book discussion included a case presentation with each participant reviewing and analyzing a different HIA case from the PEW Charitable Trusts website (PEW Health Impact Project, 2020). The group also discussed potential HIA topics that could be conducted in Marion County.

The second half of the year was used to meet the objective to conduct a HIA on a local project or policy. To accomplish this objective, the learning collaborative worked with the graduate Health Impact Assessment course at IU FSPH. The HIA Learning Collaborative generated a problem statement for the City of IndianapolisMarion County, stating a need for more access to parks and green space. According to the Trust for Public Land, Park Score Index (2019), only $35 \%$ of Indianapolis residents have access to a park within a 10-minute walk, compared to the national average of 54\%. The 10-Minute Walk Campaign, a partnership between the National Recreation and Park Association (NRPA) and the Trust for Public Land, uses the 10-minute walk as a benchmark. The project calls on cities across the U.S. to "Make the $100 \%$ Promise to make sure that everyone in your city has safe, easy access to a quality park within a 10-minute walk of home by 2050" (NRPA, 2019, para 1). Two topics were chosen by the HIA collaborative that could address the statement of need for more parks and greenspace access within the City-County's current funding limitations. This includes, 1) opening access or allowing shared use agreements to school grounds and 2) green schoolyards in Indianapolis schools to increase greenspace access. Two HIA Learning Collaborative members presented an overview on the benefits to communities of having open access to school grounds and the health benefits of green schoolyards for healthy communities and suggested assessment tools that could be used to explore these topics. The students conducted windshield surveys to begin to learn about two neighborhoods that could be used for the HIA topics. The students conducted interviews of school personnel using the assessment tools that were recommended. An additional HIA that updated a previous HIA performed to support building a grocery store in a food desert was conducted by a third group of students, and two other HIA Learning Collaborative members assisted them with demographic data to use as part of the assessment of their area.

The final HIA Learning Collaborative meeting included power point presentations by a student representative of each of the HIA projects. A good question and answer discussion occurred after each presentation.

\section{Method of Evaluation}

Two members of the collaborative created a survey in Survey Monkey in order to gather data to evaluate the overall HIA Learning Collaborative experience and to assess whether or not the learning objectives were met. The survey consisted of 11 questions: nine were multiple choice and two were open-ended. The survey link was disseminated to all HIA Learning Collaborative members through email. Of the eight members who regularly participated, seven group members completed the survey. Once responses from all members were collected, the results were exported into Microsoft Excel for analysis. Frequencies were calculated and graphs were generated using Microsoft Excel. A copy of the actual survey can be found in Appendix A.

\section{Results of Survey}

The nine multiple choice questions were answered by all seven respondents. The results are displayed in the section below. 
Table 1: Number and percentage of respondents who felt that the HIA Learning Collaborative objectives were met

\begin{tabular}{|l|c|c|}
\hline HIA Learning Collaborative Objective & N & Percent \\
\hline $\begin{array}{l}\text { Describe the purpose, benefits, and challenges of a Health Impact } \\
\text { Assessment }\end{array}$ & 7 & $100.00 \%$ \\
\hline $\begin{array}{l}\text { Develop an in-depth knowledge of the process and analytic methods used in } \\
\text { the assessment step }\end{array}$ & 6 & $85.71 \%$ \\
\hline $\begin{array}{l}\text { Demonstrate the ability to think critically and analyze how the findings } \\
\text { related to policy decisions }\end{array}$ & 6 & $85.71 \%$ \\
\hline Conduct an HIA on a local project/ process/ or policy & 3 & $42.86 \%$ \\
\hline
\end{tabular}

One hundred percent (7/7) of HIA Learning Collaborative members who completed the survey reported that they believed Objective 1 , "describe the purpose, benefits, and challenges of a Health Impact Assessment," was met during the allotted time. Nearly $86 \%$ $(6 / 7)$ of HIA Learning Collaborative members who completed the survey reported that the believed Objectives 2 and 3, "develop an indepth knowledge of the process and analytic methods used in the assessment step" and "demonstrate the ability to think critically and analyze how the findings related to policy decisions," respectively, were met. Nearly $43 \%$ (3/7) of HIA Learning Collaborative members who completed the survey reported that they believed Objective 4, "conduct an HIA on a local project/ process/ or policy," was met.

Overall, participants responded that using in person sessions with a zoom option was accommodating (Pre COVID-19 restrictions). The majority reported that using the Canvas site for resources and minutes was useful. The majority reported the book was helpful to access the baseline content. An adequate number of meetings were held with 10 total meetings over the calendar year. The majority of participants reported they have adequate personnel to conduct an HIA and feel confident to lead an HIA in the future.

\section{Future/ Next Steps}

Several ideas were generated from the survey for potential HIAs in Marion County. This includes the following:

- Determining the health impact of the future proposed transit lines

- Identifying the health impacts of zoning land use changes

- Examining the health impacts of the proposed I-70-I-65 freeway improvement project

There is also interest in continuing the HIA Learning Collaborative by expanding the membership and using the collaborative to provide technical assistance when participant organizations are ready to begin a HIA. There is need to seek out additional funding to further expand HIA efforts. The group is also interested in better collaboration between the county health department and the City of Indianapolis to expand on the Health in All Policies work that has begun. 


\section{References}

American Public Health Association. (2012). Health in All Policies. American Public Health Association. Health impact assessment: a tool to benefit health in all policies. American Public Health Association. http://www.apha.org/NR/rdonlyres/171AF5CD-070B-4F7C-AOCD- OCA3A3FB93DC/O/ HIABenefitHIth.pdf.

Healthy People 2020 Advisory Committee. (2010). Healthy People 2020: An Opportunity to Address

Societal Determinants of Health in the U.S. Healthy People Advisory Committee. https://www.healthypeople. gov/sites/default/files/SocietalDeterminantsHealth.pdf

Ross, C.L., Orenstein, M., \& Botchwey, N. (2014). Health Impact Assessment in the United States. New York: Springer Publications.

Pew Charitable Trusts). (2020). Health Impact Projects Health Notes. https://www.pewtrusts.org/en/ projects/health-impact-project

National Recreation and Park Association. (2019). Trust for public land: 10 minute walk campaign: Are you 100\% in? 10 Minute Walk.Org https://10minutewalk.org/\# Join-us 


\section{Appendix A}

\section{Health Impact Learning Assessment Learning Collaborative}

1. Please select which of the following objectives you felt were reached during the learning collaborative (choose all that apply):

$\square$ Describe the purpose, benefits, and challenges of a Health Impact Assessment

$\square$ Develop an in-depth knowledge of the process and analytic methods used in the assessment step

$\square$ Demonstrate the ability to think critically and analyze how the findings related to policy decisions

$\square$ Conduct an HIA on a local project/ process/ or policy

2. Did you feel that the setup of the learning collaborative (meeting in person or via zoom) was accommodating?

$\square$ Very accommodating

$\square$ Accommodating

$\square$ Neutral

$\square$ Not very accommodating

$\square$ Not accommodating at all

3. How helpful was it to use Canvas for sharing articles and PowerPoint presentations?

$\square$ Very helpful

$\square$ Helpful

$\square$ Neutral

$\square$ Not very helpful

$\square$ Not at all helpful

$\square$ N/A, I did not have access to Canvas

4. How useful was the book (Health Impact Assessment in the United States) in learning about HIAs and meeting the learning collaborative objectives (listed in question 1)?
$\square$ Very useful
$\square$ Useful
$\square$ Neutral
$\square$ Not very useful
$\square$ Not useful at all

5. How do you feel about the number of meetings for the HIA LC?

$\square$ Too many meetings

$\square$ Adequate number of meetings

$\square$ Not enough meetings 
6. Do you believe that your organization has the capacity to complete a HIA?
$\square$ Yes
$\square \quad$ No
$\square$ Undecided

7. After participating in the HIA Learning Collaborative, how confident would you feel leading a HIA?
$\square$ Very confident
$\square$ Confident
$\square$ Neutral
$\square$ Not very confident
$\square$ Not confident at all

8. After participating in the HIA Learning Collaborative, how confident would you feel being a part of a HIA?
$\square$ Very confident
$\square$ Confident
$\square$ Neutral
$\square$ Not very confident
$\square$ Not confident at all

9. Do you think Health Notes would be a useful tool in the future?

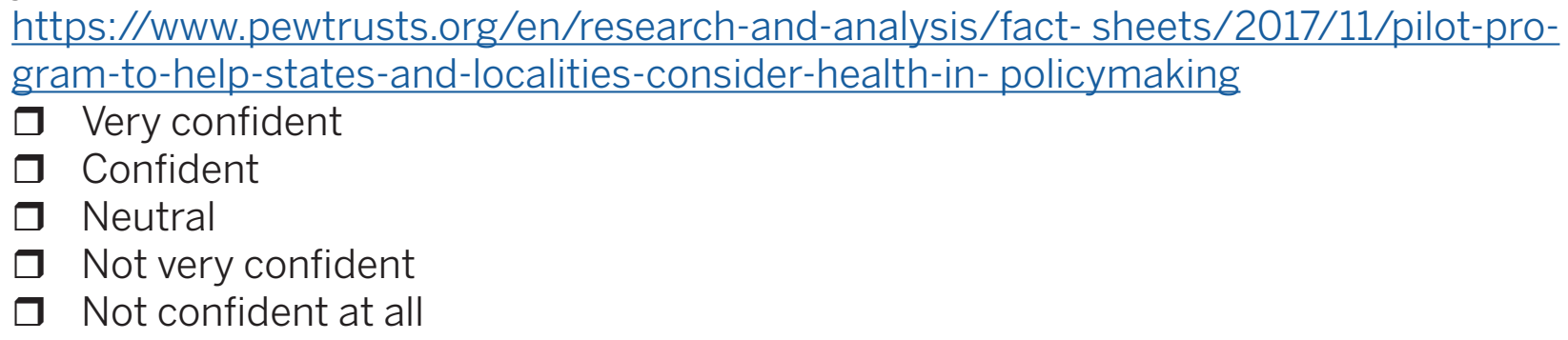

10. What do you think is needed to conduct a HIA in the future?

11. Please list ideas for potential HIAs in the space below. 


\section{CORRESPONDING AUTHOR}

Cynthia Stone, DrPH, MSN, RN

Department of Health Policy and Management

Indiana University-Purdue University Indianapolis

1050 Wishard Blvd. RG 5128

Indianapolis, IN 46202

cylstone@iu.edu

\section{CHIA Staff:}

\section{Editor-in-Chief}

Cynthia Stone, DrPH, RN, Professor, Richard M. Fairbanks School of Public Health, Indiana University-Purdue University Indianapolis

\section{Journal Manager}

Angela Evertsen, BA, Richard M. Fairbanks School of Public Health, Indiana University-Purdue University Indianapolis

Chronicles of Health Impact Assessment Vol. 5 Issue 1 (2020) DOI: 10.18060/23874

(C) 2020 Author(s): Stone, C.; Redenz, A.; Bochenek, A.; Hansotte, E.

cc This work is licensed under a Creative Commons Attribution 4.0 International License 